Illinois State University

ISU ReD: Research and eData

Theses and Dissertations

3-8-2017

\title{
The Influence of Online Social Networking Sites on Selection into a Dietetic Internship
}

Noel Lorraine Konken

Illinois State University, nlkonke@ilstu.edu

Follow this and additional works at: https://ir.library.illinoisstate.edu/etd

Part of the Human and Clinical Nutrition Commons

\section{Recommended Citation}

Konken, Noel Lorraine, "The Influence of Online Social Networking Sites on Selection into a Dietetic Internship" (2017). Theses and Dissertations. 688.

https://ir.library.illinoisstate.edu/etd/688

This Thesis is brought to you for free and open access by ISU ReD: Research and eData. It has been accepted for inclusion in Theses and Dissertations by an authorized administrator of ISU ReD: Research and eData. For more information, please contact ISUReD@ilstu.edu. 


\title{
THE INFLUENCE OF ONLINE SOCIAL NETWORKING \\ SITES ON SELECTION INTO A \\ DIETETIC INTERNSHIP
}

\author{
Noel L Konken
}

49 Pages

Background: Acceptance into a Dietetic Internship (DI) Program is a competitive application process where the growing number of applicants exceeds the number of available positions. Because of this, Dietetic Internship (DI) directors may need to outsource external applicant information on social networking sites (SNS) to better differentiate among top candidates. Objective: The purpose of this study surveying didactic program in dietetics (DPD) directors and DI directors was to evaluate the effects of SNS education on DPD match rate and how DI directors utilize SNS while reviewing potential candidates' application materials.

Design: DPD and DI directors were emailed a link to an anonymous, web-based survey to obtain information from DPD directors regarding spring 2016 DI match data and DI directors regarding the frequency and beliefs for online vetting of potential candidates.

Participants: All DPD and DI directors from programs accredited by the Accreditation Counsel for Education in Nutrition and Dietetics (ACEND) in the United States and Puerto Rico were invited to participate. In total, 99 DPD directors (44.6\%) and 158 DI directors (64.2\%) responded to the online survey.

Results: Although the majority of DI programs did not use online research methods to evaluate potential candidates, statistical analysis revealed programs that offer a combined masters and DI 
reviewed a significantly greater number of candidates on SNS or internet search engines than programs that only offer a DI. Additionally, the majority of DI directors agreed online professionalism should be a factor for admission into a DI program. However, while only half of DPD directors reported educating students on professional use of SNS, the majority of DPD directors believed educating students on the influence of social networking to be important with the topics "professional online presence" and "e-portfolios" to have the greatest perceived benefit. Still, SNS education did not significantly alter a DPD programs match rate during the spring 2016 match.

Conclusions: DI programs combined with a masters degree survey a greater number of applicants online, which may prompt applicants to such programs to adopt higher privacy settings on their personal SNS. At this time, incorporating education on SNS within DPD curriculum may have minimal effect on match rate; however finding unprofessional information online may have a greater effect on a potential candidate's acceptance versus finding no information at all.

KEYWORDS: Dietetics, Internship, Social networking 


\title{
THE INFLUENCE OF ONLINE SOCIAL NETWORKING \\ SITES ON SELECTION INTO A \\ DIETETIC INTERNSHIP
}

NOEL L. KONKEN

\author{
A Thesis Submitted in Partial \\ Fulfillment of the Requirements \\ for the Degree of \\ MASTER OF SCIENCE \\ Department of Family and Consumer Sciences \\ ILLINOIS STATE UNIVERSITY
}


(C) 2017 Noel L Konken 


\section{THE INFLUENCE OF ONLINE SOCIAL NETWORKING}

SITES ON SELECTION INTO A

DIETETIC INTERNSHIP

NOEL L. KONKEN

COMMITTEE MEMBERS:

Julie Schumacher, Chair

Jennifer Banning

Jennifer Barnes 


\section{ACKNOWLEDGMENTS}

First, I would like to offer immense gratitude to my committee chair, Dr. Julie Schumacher, for her continuous support and valued insight throughout the entirety of this research process. However, not only has Dr. Julie Schumacher played a large role in the completion of this document, she has played an even larger role in my pursuit to be a Didactic Program in Dietetics (DPD) Director by enhancing my educational career in finding unique opportunities that match my future objectives. Without a doubt, she has been the most positive and influential role model from whom I have ever had the privilege to learn.

Furthermore, I would like to show appreciation for my committee members, Dr. Jennifer Banning and Dr. Jennifer Barnes, for their analytical contribution in finalizing this document. I have prized the various perspectives from every member of my committee as they have been an inspiration for me to continue further research. Additionally, I wish to thank the Illinois State University Dietetic Internship Class of 2017, for without their support and friendship, the journey to my master's would have been far less enjoyable.

To finish I wish to dedicate this document to my father, W. Lee Konken, who has silently taught me the importance of working hard with humility while being the supportive foundation our family depends upon, as well as my mother, Sandra Konken, who's selflessness never fails to attest that no one can truly love you like your mother. Immense gratitude is also due to my older siblings, Kara, Andrea, and Eric, for providing me with guidance in growing up to achieve anything I set my sights on.

N. L. K 


\section{CONTENTS}

Page

ACKNOWLEDGMENTS

$\begin{array}{ll}\text { CONTENTS } & \text { ii }\end{array}$

TABLES $\quad$ iv

CHAPTER I. THE INFLUENCE OF SOCIAL NETWORKING ON SELECTION INTO A

$\begin{array}{ll}\text { DIETETIC INTERNSHIP } & 1\end{array}$

Introduction $\quad 1$

$\begin{array}{ll}\text { Methods } & 3\end{array}$

Sampling Procedure 3

Survey Design $\quad 3$

Data Collection $\quad 4$

Statistical Analysis $\quad 4$

Results

$\begin{array}{ll}\text { Demographics } & 6\end{array}$

Types, Frequency, and Use of Social Media Sites by DI Directors 7

Unprofessional Information $\quad 9$

$\begin{array}{ll}\text { Match Rate } & 10\end{array}$

$\begin{array}{ll}\text { Social Networking Education } & 11\end{array}$

$\begin{array}{ll}\text { Discussion } & 12\end{array}$

DI Directors Online Vetting Behavior $\quad 12$

$\begin{array}{ll}\text { Unprofessional Information } & 13\end{array}$

$\begin{array}{ll}\text { Social Networking Education } & 14\end{array}$ 
$\begin{array}{ll}\text { Conclusion } & 15\end{array}$

$\begin{array}{ll}\text { References } & 18\end{array}$

CHAPTER II: EXTENDED LITERATURE REVIEW 24

$\begin{array}{ll}\text { Steps to becoming a Registered Dietitian Nutritionist } & 24\end{array}$

$\begin{array}{ll}\text { Centralized Match Process with DICAS } & 26\end{array}$

Online Vetting of Social Networking Sites 26

$\begin{array}{ll}\text { Social Networking Education } & 28\end{array}$

$\begin{array}{ll}\text { Conclusion } & 29\end{array}$

$\begin{array}{ll}\text { References } & 30\end{array}$

APPENDIX A: SURVEY INSTRUMENT FOR DPD DIRECTORS 33

APPENDIX B: SURVEY INSTRUMENT FOR DI DIRECTORS 38

APPENDIX C: INITIAL SURVEY ACCESS EMAIL FOR DPD DIRECTORS 42

APPENDIX D: INITIAL SURVEY ACCESS EMAIL FOR DI DIRECTORS 43

APPENDIX E: INFORMED CONSENT FOR DPD DIRECTORS 44

APPENDIX F: INFORMED CONSENT FOR DI DIRECTORS 45

APPENDIX G: REMINDER EMAIL \#1 FOR DPD DIRECTORS 46

APPENDIX H: REMINDER EMAIL \#2 FOR DI DIRECTORS 47

APPENDIX I: FINAL EMAIL REMINDER EMAIL FOR DPD DIRECTORS 48

APPENDIX J: FINAL EMAIL REMINDER EMIAL FOR DI DIRECTORS 49 


\section{TABLES}

Table

Page

1. Demographic characteristics of DPD directors who completed the online survey

2. Demographic characteristics of DI directors who completed the online survey

3. Percentage of applicants evaluated by internships through search engines or social networking sites

4. Social networking topics DPD directors educate on to assist students with the DICAS application 


\section{CHAPTER I: THE INFLUENCUE OF SOCIAL NETWORKING ON SELECTION INTO A DIETETIC INTERSHIP INTRODUCTION}

Obtaining a career as a registered dietitian nutritionist (RDN) is a systematic process set by the Accreditation Counsel for Education in Nutrition and Dietetics (ACEND) of the Academy of Nutrition and Dietetics (AND). After students have received verification statements indicating they have successfully completed a Didactic Program in Dietetics (DPD), students are eligible to participate in the dietetic internship (DI) match process. According to ACEND, this match procedure follows a computer-based method to match student's preferences for placement into a DI program alongside the preferences of DI program directors. ${ }^{1}$ However, the number of DPD program graduates applying to DI programs has continued to exceed the number of available spots resulting in an approximate acceptance rate of 50\% throughout the past seven years. ${ }^{2}$ This discrepancy between number of applicants and number of available positions has contributed to the increasingly competitive nature of the DI application and match process.

The competitive characteristics of the DI match process are comparative to those of other health care professions. For example, medical students participate in a uniform online match system through the Electronic Residency Application Service (ERAS) in which both medical student applicants and residency programs rank one another resulting in a mutual matching process. ${ }^{3}$ Similarly, pharmacy students also partake in a streamlined matching system through the Pharmacy Online Residency Centralized application Service (PhORCAS). ${ }^{4}$ Between both disciplines of medical and pharmacy residency programs, the total national match rate for acceptance in 2016 was $50 \%$ and $69 \%$ respectively. ${ }^{5.6}$ Thus, because of the similar application 
process and rigorous competition, it can be inferred dietetics students may confront similar challenges to medical and pharmacy students during the DI application process.

With residency programs being highly competitive, programs may need to out-source external applicant information to better differentiate between top candidates. Content on personal social networking sites (SNS) has been reported to affect a student's selection into residency programs because unprofessional information could compromise a student's admission. ${ }^{7,8}$ Similarly, reviewing dietetics student's social networking sites may provide insightful information to DI directors prior to ranking their applicants for acceptance into their program. However, to date, no research has been conducted on DI directors' behavior of online vetting potential candidates into their program.

Additionally, while SNS may have an effect on student's acceptance into residency programs, most medical schools do not provide education via lectures or educational activities regarding professional and appropriate social networking practices, nor do they have policies addressing inappropriate online behavior on SNS. ${ }^{9}$ Given the competitive nature of dietetic internships, maintaining a professional online presence may benefit a student during the application process. Currently, there is no set curriculum for DPD directors in educating dietetic students on the professional use of social networking sites, nor any indication on how social networking sites are utilized within the profession. With the emerging adoption of online screening in medical residency programs, this research study aims to answer the following research questions: 1.) What are the types, frequency, and use of information gathered from social networking sites referenced by Dietetic Internship Directors? 2.) How does unprofessional information found online effect an applicant's acceptance into a dietetic internship program? 3.) 
Is there a difference in the match rate of DPD Programs that include education on professional social networking sites and those programs that do not?

\section{METHODS}

\section{Sampling Procedure}

Program Directors from ACEND accredited DPD and DI Programs were recruited via email using publically available email addresses from the Academy of Nutrition and Dietetics webpage: www.eatright.org. This study intended to sample the entire population of DPD and DI directors by sending recruitment emails to all 234 DPD Programs and 247 DI Programs currently accredited in the United States and Puerto Rico during the time of the study. DPD and DI directors were given information regarding the study's purpose to allow them to determine their willingness to participate. Demographics of each participant such as age, gender, and educational background were collected to generate sample characteristics. Participants choosing to participate in the study were assured confidentiality.

\section{Survey Design}

Two web-based surveys were developed utilizing the online platform, Select Survey. Survey questions were adapted from a previous research study ${ }^{8}$ and thesis research. ${ }^{10}$ Permission-for-use of both surveys was obtained from the authors. Both surveys underwent slight adaptation from the original versions to maintain relevance to the targeted population of DPD and DI directors.

The online survey administered to DI directors (Appendix B) was designed to determine the types, frequency, and use of social networking sites that DI directors utilize. DI Directors were also asked about their personal knowledge and opinion on the use of social networking sites and online search engines during the DI application process using a five-point Likert scale from 
strongly disagree to strongly agree. Similarly, the survey administered to DPD Directors

(Appendix A) asked participants about their personal knowledge and opinions in the use of social networking sites and online search engines during the DI application process using a five-point Likert scale from strongly disagree to strongly agree. However, this survey to DPD directors also gathered information on whether or not their program educates their students on the professional use of social networking sites and collected statistical data on each program's match results from the December 2015 and April 2016 match period. Each 26-question survey underwent previous pilot testing to assure clarity and relevance to the research topic via content and face validity.

\section{Data Collection}

In May of 2016, each web-based survey was emailed to all ACEND accredited DPD and DI program directors (Appendix C, Appendix D) in the United States and Puerto Rico at that time. During the 1-month survey collection period, two reminder emails were sent to all DPD and DI program directors (Appendix G, Appendix H, Appendix I, Appendix J). All communication to subjects via email addressed the voluntary and confidential nature of the survey. An electronic consent form (Appendix E, Appendix F) was obtained from all participants prior to accessing the online survey. By clicking, "Yes, I consent to participate in this study and am at least 18 years old" on the informed consent form, participant's indicated their agreement to participate in the study.

\section{Statistical Analysis}

Information was reported on response rate of distributed surveys with information on the number of participants that did not complete a survey. Descriptive statistics were summarized through frequency and percentages. Inferential statistics were utilized to make generalizations about the sample population's characteristics. All analyses were completed utilizing IBM SPSS 
Statistics 22 . The significance value was set at the $p=.05$ value with all significance values below this set-point considered statistically significant.

Pearson Correlation Coefficients were used to examine the relationship between DI directors' use and opinions on researching applicants online during the application process. Independent $t$-tests were performed to determine any differences between DI internship program types and online vetting behavior. A one-sample $t$-test was utilized to test if there was a significant difference between the average DI match rate of the DPD respondents of the survey and the national average of the spring 2016 match period. Final results have been presented in tables for interpretation of the results. Statistical significance has been reported, as well as how the results correspond with the original three research questions.

\section{RESULTS}

The survey designed for DPD directors was sent to 222 current DPD directors with 99 respondents (44.6\%) to the online instrument. Of these 99 respondents, 34 were excluded in all analysis because of insufficient completion of the survey. From the remaining 65 subjects, an additional 14 respondents were excluded from analyses pertaining to match results due to missing data pertaining to the number of students who applied or were matched to DI programs. As a result, 52 subjects were included in analyses regarding match rate among DI programs and 65 subjects were included in analysis regarding all other inquiries.

The survey designed for DI directors was sent to 246 current DI directors with 158 respondents $(64.2 \%)$ to the online instrument. In total, 59 respondents were excluded in all analysis because of insufficient completion of the survey. As a result, 99 subjects were included in all analyses pertaining to DI directors. 


\section{Demographics}

Overall, $78 \%(n=49)$ of all DPD directors served within their job description at their current institution for one year or more. The largest portion $(35 \%, \mathrm{n}=22)$ of DPD directors served between one and five years. The second largest portion of respondents at $22 \%(n=14)$ served less than one year. When asked their age, $76 \%(n=48)$ of all DPD directors indicated they were 41 years of age or older with the largest grouping of subjects $(33 \%, \mathrm{n}=21)$ between the ages of 51 and 60 years old. No respondents $(n=0)$ indicated to be between the ages of 18 and 30 years old, leaving the remaining $24 \%(n=15)$ of subjects between 31 and 40 years old.

Also, 65\% $(n=41)$ of all DPD directors served at undergraduate DPD institutions that offer either a DI program, Individualized Supervised Practice Pathway (ISPP) option, or both. The remaining $35 \%(n=22)$ of subjects served at institutions with no DI nor ISPP options available. Of those $65 \%$ of DPD directors that did serve at institutions with a DI program, ISPP option, or both, $88 \%(\mathrm{n}=36)$ sit on the advisory board when selecting DI or ISPP candidates.

Of the 99 DI directors included in this study, $76 \%(n=74)$ of subjects were 41 years or older. The remaining $23 \%(n=23)$ of subjects were 40 years or younger with only $2 \%(n=2)$ of subjects between the ages of 18 and 30. The majority $(74 \%, \mathrm{n}=72)$ of DI directors reviewed candidate applications for dietetic internship programs. Of the remaining $26 \%$ of subjects, $25 \%$ $(n=24)$ reviewed applications for combined masters and dietetic internship programs and $1 \%$ $(n=1)$ did not review applications at all. No subjects $(n=0)$ reviewed ISPP candidate applications. The average number of applications respondents received during the spring 2016 match was 79.9 applications $(\mathrm{sd}=55.7)$ with a minimum of five and a maximum of 285 applications.

The majority $(57 \%, \mathrm{n}=53)$ of DI directors served for a DI program that does not participate in any form of social media. Of the remaining $43 \%$, the most popular forms of social 
media platforms DI programs reportedly participated in included Facebook $(30 \%, \mathrm{n}=28)$ and LinkedIn $(8 \%, \mathrm{n}=7)$. However, when DI directors were asked if they had a personal profile on a social networking website, only $14 \%(n=13)$ of subjects indicated they did not participate in social media. Similarly to DI programs, most DI directors also participated in Facebook (76\%, $\mathrm{n}=71)$ and LinkedIn $(67 \%, \mathrm{n}=67)$. Other modes of social media DI directors used for personal inquiries included Instagram $(29 \%, \mathrm{n}=27)$ and Twitter $(24 \%, \mathrm{n}=22)$.

A Pearson correlation coefficient showed a significant, but weak, positive relationship when comparing the total number of social media outlets DI programs and their DI directors participated in $(\mathrm{r}=.296, \mathrm{p}=.004)$. A Pearson correlation coefficient also showed a significant, but weak, negative relationship when comparing age with total number of social media outlets DI directors participate in $(\mathrm{r}=-.317, \mathrm{p}=.002)$. Please refer to Table 1 and Table 2 for a complete listing of demographic information for DPD and DI directors who responded to the online survey.

\section{Types, Frequency, and Use of Social Media Sites by DI Directors}

DI directors were asked the types and frequency that both themselves and their program's admission board utilized SNS when evaluating potential candidates. The majority at $69 \%(\mathrm{n}=64)$ of admission boards did not use online research methods to evaluate potential candidates, whereas $15 \%(n=14)$ of admission boards utilized both SNS and internet search engines when evaluating applicants. Of the remaining 16\%, $8 \%(n=7)$ of DI program admission boards utilized SNS exclusively, 2\% (n=2) utilized internet search engines exclusively, and 6\% $(n=6)$ were unsure. In determining the frequency of use for admission boards that did utilize online resources when evaluating potential candidates, $14 \%(n=13)$ evaluated $25 \%$ or less of all applicants through search engines or SNS while $11 \%(n=11)$ evaluated $26 \%$ or greater of all applicants 
through search engines or SNS. A total of five (5\%) subjects reported their admission board reviewed $100 \%$ of all potential candidates.

The results were similar when DI directors were asked if they personally utilized online resources to evaluate potential candidates. Likewise, the majority at $73 \%(n=67)$ did not use online research methods $(n=67)$. Nevertheless, of DI directors that did utilize online resources, $14 \%(n=13)$ utilized both SNS and internet search engines. Of the remaining $12 \%, 10 \%(n=9)$ of DI directors utilized SNS exclusively and 3\% $(n=3)$ utilized internet search engines exclusively. Furthermore, of DI directors that did utilize online research methods, $14 \%(\mathrm{n}=14)$ evaluated $25 \%$ or less of all applicants through search engines or SNS $(n=14)$ and $12 \%(n=12)$ evaluated $26 \%$ or greater of all applicants through search engines or SNS. Only $4 \%(n=4)$ evaluated $100 \%$ of all applicants. Correlation analysis revealed neither age nor number of social media outlets DI directors or DI programs participated in had a significant relationship with the percentage of applications reviewed on SNS and internet search engines.

An independent sample $t$-test comparing the difference between DI programs revealed a significant difference $(\mathrm{t}=2.32, \mathrm{df}=89, \mathrm{p}=.022)$ between programs that offer a combined masters and DI and programs that offer only a DI. On average, programs that offer a combined master's and DI have program admission boards that reviewed a greater number of candidates on SNS or internet search engines $(\mathrm{m}=1.45, \mathrm{sd}=2.15, \mathrm{n}=22)$ than program admission boards that only offer a DI $(\mathrm{m}=.55, \mathrm{sd}=1.37, \mathrm{n}=69)$.

In addition, DI directors were asked on a 5-point Likert scale ( $1=$ strongly disagree, 5=strongly agree) about their use and opinion of evaluating potential candidates on SNS and internet search engines. Most subjects $(67 \%, \mathrm{n}=62)$ disagreed or strongly disagreed that their admission board normally searches for additional information on applicants that is not found in 
their applications through both internet searches and SNS. Consequently, $12 \%(n=11)$ agreed or strongly agreed their admission board normally searches for additional information on applicants through internet searches, and 14\% ( $\mathrm{n}=13)$ agreed or strongly agreed their admission board normally searches for additional information on applicants through SNS.

However, when asked if DI programs should use internet searches or SNS to obtain additional information about applicants that is not included in their application only $29 \%(\mathrm{n}=29)$ of subjects strongly disagreed or disagreed that DI program admissions should use internet search engines, and $28 \%(\mathrm{n}=28)$ strongly disagreed or disagreed that DI program admissions should use SNS. The majority of subjects neither agreed nor disagreed that DI programs should use internet search engines and SNS at $42 \%(n=39)$ and $44 \%(n=40)$ respectively. To add, $27 \%$ $(n=25)$ of subjects agreed or strongly agreed that DI programs should use internet searches and $25 \%(\mathrm{n}=23)$ agreed or strongly agreed that DI programs should use SNS.

When DI directors were asked about plans to search for additional information on potential candidates in the future, $55 \%(n=55)$ of subjects disagreed or strongly disagreed that their admission board plans to search for additional applicant information on an internet search engine, and $53 \%(n=49)$ on a SNS. Only $15 \%(n=14)$ of subjects agreed or strongly agreed that their admission board plans to search for additional applicant information on an internet search engine and $17 \%(n=16)$ on SNS in the future.

\section{Unprofessional Information}

DI directors were asked on a 5-point Likert scale from strongly disagree to strongly disagree about whether or not unprofessional information found on internet search engines or SNS altered their decision when reviewing potential candidates online. The majority of subjects $(54 \%, \mathrm{n}=50)$ agreed or strongly agreed that online professionalism should be a factor for 
admission into a DI program. Additionally, 31\% (n=29) of subjects neither agreed nor disagreed on the matter, whereas the remaining $15 \%(n=14)$ disagreed or strongly disagreed that online professionalism should be an admission factor.

When asked about finding unprofessional information on an applicant's SNS, 53\% $(n=49)$ of subjects agreed or strongly agreed that the unprofessional material would compromise an applicant's admission into their DI program. Of the remaining subjects, $29 \%(\mathrm{n}=27)$ neither agreed nor disagreed that unprofessional material would compromise an applicant's status while only $18 \%(n=17)$ disagreed or strongly disagreed. Still, $77 \%(n=70)$ and $73 \%(n=66)$ of subjects disagreed or strongly disagreed that their admission board has decided to not admit and applicant because of unprofessional information found on internet search engines and SNS respectively. A total of $2(2 \%)$ subjects agreed or strongly agreed their admission board has indeed not admitted an applicant due to unprofessional information found on an internet search engine, but a total of $6(7 \%)$ subjects agreed or strongly agreed their admission board has not admitted an applicant due to unprofessional information found on SNS.

\section{Match Rate}

Two different DPD match rates were calculated including total match rate, which included all students that were enrolled in the DPD program at the time of the survey along with those that had previously graduated who applied using DICAS during the spring 2016 match period, and current match rate, which included students that were enrolled in the DPD program at the time of the survey and applied using DICAS during the spring 2016 match period. Overall, the average total match rate for the 52 participating DPD programs in this study was $63.7 \%$. This average was slightly lower than the average current match rate for the participating DPD programs at $66.6 \%$. As reported by ACEND, the national average during the spring 2016 match 
utilizing DICAS was $51 \%$. Thus, by using a one-sample $t$-test, we can determine the survey respondents had a significantly higher total match rate $(t=3.791, \mathrm{df}=50, \mathrm{p}<.0001)$ than the national average of the same year. Please refer to Table 2 for a complete reference of the averages and standard deviations for both match rates.

\section{Social Networking Education}

DPD directors were asked to identify whether or not they educated on various social networking topics to assist DPD students with the DICAS application process by means of course curriculum or informational workshops. In regards to course curriculum, half of the subjects $(50 \%, \mathrm{n}=28)$ reported they do incorporate the topic of e-portfolios into their course curriculum. Other popular topics included in DPD course curriculum included general social networking $(41 \%, \mathrm{n}=23)$ and building a professional online presence $(34 \%, \mathrm{n}=19)$. Only $29 \%$ $(n=16)$ of subjects indicated they do not include any topics regarding social networking into course curriculum. When reporting topics DPD directors included during informational workshops to assist DPD students with the DICAS application process, 34\% $(n=19)$ of all subjects indicated they educated on either e-portfolios, general social networking, or both. Similarly, 30\% $(\mathrm{n}=17)$ of subjects indicated they do not include any topics of social networking into information workshops. A full list of frequencies regarding the topics DPD directors incorporated into course curriculum and informational workshops can be found in Table 4. Most DPD directors $(31 \%, \mathrm{n}=16)$ incorporated one of the listed topics into course curriculum; however, in regards to informational workshops, most DPD directors $(41 \%, \mathrm{n}=21)$ did not include any of the listed topics. A Pearson's correlation indicates a strong positive relationship $(\mathrm{r}=.61, \mathrm{p}<.01)$ between the total number of SNS topics covered within course curriculum and informational workshops. 
When determining the differences in match rates between DPD programs that included SNS topics within their course curriculum or informational workshops and those that do not, independent $t$-tests indicated a higher average total match rate and current match rate among DPD programs that included at least one of the listed SNS topics, however these findings were insignificant. Additional $t$-test analysis was conducted on each SNS topic. Similarly, there were no significant differences in total match rate or current match rate between each SNS topic.

DPD directors were asked on a 5-point likert scale ( $1=$ not important at all, 5=extremely important) how important they believed educating students on the influence of social networking is when determining whether certain individuals will be matched to a dietetic internship. The majority $(62 \%, \mathrm{n}=35)$ found educating students on the influence of social networking to be important or extremely important. DPD directors were also asked to choose a single topic they believed was, or had the potential to be the most effective topic for assisting their DPD students with the DICAS match process. The topics of professional online presence $(37 \%, \mathrm{n}=20)$ and eportfolios $(35 \%, \mathrm{n}=19)$ were the most widely perceived topics to have the greatest benefit. However, these perceived topics do not directly correlate with the topics most frequently reported to be covered within course curriculum and informational workshops.

\section{DISCUSSION}

\section{Directors Online Vetting Behavior}

This research indicates that the majority of DI programs do not use online research methods to evaluate potential candidates prior to acceptance into their DI program. This finding is similar to those of medical residency programs. ${ }^{8,11,12}$ However, a significant difference found that DI programs that are combined with a master's degree reviewed a greater number of applicants on SNS or internet search engines than programs that only offered a DI. This 
difference may benefit dietetics students in suggesting students applying to DI programs combined with a master's degree should adopt stricter privacy settings on personal SNS prior to submitting their final DICAS application. Additionally, this significant difference suggest student's applying to DI programs combined with a master's degree may be at higher risk of having their application deferred related to unprofessional information found online.

The majority of DI directors neither agreed nor disagreed that their program should use internet search engines to obtain additional information about applicants. This indifferent opinion regarding online vetting is supported when DI directors were asked about plans to adopt this practice in the future with the majority of respondents indicating they had no plans to pre-screen future applicants online. It can be inferred a barrier to searching applicants on internet search engines and social networking sites is not related to unfamiliarity of online vetting as the majority of the DI director respondents indicated to be somewhat or very familiar with this practice. Additionally, these results suggests DI directors do not plan to withhold from searching an applicant's name online because they believe it to be unethical as the majority of survey respondents indicated they disagreed online vetting was a violation of privacy. DI directors' opinions that searching a potential candidate online is not a violation of privacy is similar to those opinions of residency directors. ${ }^{8,11}$ According to literature, DI directors have varying job responsibilities outside of internship management including teaching responsibilities, scholarly, and service work. ${ }^{13}$ Thus, one factor relating to no intention to begin searching potential candidates online may be related to time constraints within their job description.

\section{Unprofessional Information}

Notably, the majority of DI directors agreed online professionalism should be a factor in DI program admission and that unprofessional material should compromise an applicant's 
acceptance into a DI program. However, a very small minority of DI directors reported to agree that their admission board has indeed not admitted an applicant due to unprofessional information found online. These findings are supported by similar research studies in medical residency programs where program directors believed unprofessional behavior online should play a factor when accepting students into their program; yet, less than half of respondents reported they have decided against a student related to such findings. ${ }^{8,11}$

However, the definition of unprofessionalism on SNS for dietetic students still remains unclear. Because of the increase in social media in health care professions, many national health care organizations have created social media polices, such as the American Medical Association, the American College of Physicians, and the American Nurses Association. The American Medical Association's formal policy indicates participation in SNS may help physicians develop a professional online presence; however, it can also negatively affect their reputations and have consequences on their medical careers. ${ }^{14}$ Within the profession of dietetics, the Academy of Nutrition and Dietetics has only created a social media policy intended for contributors to its website: www.eatright.org. ${ }^{15}$ Thus, overall professionalism remains difficult to measure in the context of personal engagement on SNS.

\section{Social Networking Education}

Although half of DPD directors that responded to this survey reported incorporating some form of social networking topic into course curriculum or educational workshops for their students, there was no significant relationship between social networking education and match rate. This finding may correlate with the findings that the majority of DI programs do not yet outsource additional information from candidates using online search engines or SNS; thus, even 
if students alter their SNS to reflect professionalism, this behavior may go unnoticed during the DICAS matching process.

According to survey findings, the majority of DPD directors believe educating students on the influence of social networking was important with the perceived most effective topic of education to be developing a professional online presence. This topic is well support by the literature in that students and job seekers are aware of the benefits of maintaining a professional online presence when searching for employment. ${ }^{16,17}$

\section{Limitations}

During the spring 2016 match, the national acceptance rate as reported by ACEND was $51 \%$, whereas the DPD respondents of this survey had an average match rate of $63.7 \%$. This difference in match rate was significant indicating a potential limitation while construing the data related to match rate. Overall, it can be inferred DPD programs with a higher match rate have well established intervention strategies which may includ education on various topics of social networking. Additionally, DPD programs with a higher than average match rate may take pride in this statistic and be more willing to participate in survey research related to their DPD programs success rate leading to a response bias and skewed results that are not representative of all DPD programs nationwide.

\section{CONCLUSION}

The findings of this survey-based study examined the potential benefits of educating DPD students on various topics of social networking while applying to a DI through the DICAS match process. Of all social networking topics assessed, it was determined no one specific topic was associated with improving a DPD program's match rate when comparing DPDs that educated students on each topic and those that did not. Still, DPD programs that educated their 
students on at least one topic of social networking had a higher match rate than programs that did not educate on social networking at all; although these results were insignificant. Thus, it can be inferred specific topics regarding social networking may not specifically contribute to more successful outcomes when applying to a DI, but overall acknowledgment on the importance of social networking may play a larger factor.

This study identifies DI director's online vetting behavior; however, the majority of DI directors are not reviewing potential candidates online through internet search engines. Yet, data comparing the volume of students DI directors choose to pre-screen online shows DI programs that are combined with a master's degree review a greater number of students online than programs that only have a DI. This finding suggests students that choose to apply to combined master's and DI programs should be more aware of their presence on SNS and may wish to remove content or use higher privacy settings on their personal SNS.

Results from this study may suggest incorporating education on SNS within DPD curriculum may have no effect on student's success of getting matched to a DI. Nonetheless, with the majority of DI directors agreeing unprofessional information found online should compromise a student's acceptance into a DI program, it can be concluded finding unprofessional information online may have a great effect on a potential candidate's acceptance than finding no external information at all. Still, this study reveals this risk is minimal as very few students have indeed not been accepted into a DI because of unprofessional content found through internet search engines or personal SNS.

Further research needs to be conducted to determine whether or not social networking has practical implications in DPD curriculum. Outcomes from this study have suggested online vetting plays a more important factor during application reviews for combine master's and DI 
programs, but still the number of potential candidates reviewed continues to be on average less than $25 \%$ of all applications received. Further research is necessary to determine the which students programs choose to screen online, whether it be there top, middle, or bottom $25 \%$ rankings.

As the competitive nature of dietetic internships persists with the number of applicants surpassing the number of available spots, methods for DPD programs and students to gain a competitive advantage over their peers will continue to be a topic of interest. Maintaining a professional online presence been shown to have potential benefits in other disciplines within the health care field; thus, social networking's relevance within the dietetics profession may still merely be in its early stages. Future research is needed to determine potential implications of social networking specific to the DICAS application process. 


\section{REFERENCES}

1. Accreditation Council for Education in Nutrition and Dietetics. Dietetic internship match: program director. http://www.eatrightpro.org/resources/acend/program-directors/dieteticinternship-match-program-directors. Accessed February 23, 2017.

2. Accreditation Council for Education in Nutrition and Dietetics. Availability for dietetic internship programs. http://www.eatrightpro.org/resource/acend/students-and-advancingeducation/dietetic-internship-match-students/availability-of-dietetic-internship-positions. Accessed April 10, 2016.

3. American Academy of Family Physicians. The match: getting into a residency program. http://www.aafp.org/medical-school-residency/residency/match.html. Published 2017. Accessed February 25, 2017.

4. National Matching Services Inc. Overview of the matching program. https://www.natmatch.com/ashprmp/aboutoverview.html. Accessed February 25, 2017

5. The National Resident Matching Program. Results and Data. http://www.nrmp.org/wpcontent/uploads/2016/04/Main-Match-Results-and-Data-2016.pdf. Published April 2016. Accessed February 25, 2017.

6. National Matching Services Inc. Summary results of the match for positions beginning in 2016. https://www.natmatch.com/ashprmp/stats/2016applstats.html. Published 2016. Accessed February 25, 2017.

7. Ponce BA, Determann JR, Boohaker HA, et al. Original Reports: Social networking profiles and professionalism issues in residency applicants. An original study-cohort study. J Surg Edu. 2012,70(4):502-507.

8. Schulman CI, Kuchkarian, FM, Withum, KF, et al. Influence of social networking websites on medical school and residency selection process. Postgrad Med J. 2013;89(1049):126-130.

9. Barker, AL, Wehbe-Janek, H, Bhandari NS, et al. Original Contribution: A national cross-sectional survey of social networking practices of U.S. anesthesiology residency program directors. J Clin Anesth. 2012;24(8):618-624.

10. Uhlman, JR, Schumacher J, Ma YJ, et al. Intervention strategies utilized by didactic programs in dietetics to increase the match rate of undergraduate students to accredited dietetic internships [master's thesis]. Normal: Illinois State University; 2015.

11. Cain J, Scott DR, Smith K. Use of social media by residency program directors for resident selection. Am J Health Syst Pharm AJHP. 2010;67(19):1635-1639.

12. Go PH, Klaassen, Z, Chamberlain RS. Original report: Attitudes and Practices of Surgery Residency Program Directors Toward the Use of Social Networking Profiles to Select Residency Candidates: A Nationwide Survey Analysis. J Surg Edu. 2012;69(3):292-300. 
13. Abad-Jorge A, Potter J. A survey of master's dietetic internship programs in the U.S: Program director roles, employment and curriculum delivery models. J Acad Nutr Diet. 2016;116:71.

14. American Medical Association. AMA policy: Professionalism in the use of social media. file:///C:/Users/Lee/Downloads/4886-65533-2-SP.pdf. Published 2012. Accessed February 24, 2017.

15. Helm J, Jones RM. Practice paper of the academy of nutrition and dietetics: social media and the dietetics practitioner: opportunities, challenges, and best practices. J Acad Nutr Diet. 2016;116(11):1825-1835.

16. Kelly S, Christen S, Gueldenzoph Snyder S. An analysis of effective online reputation management: a critical thinking social media activity. J Reas Bus Edu. 2016;55(1):24-35.

17. Smith, A. Pew Research Center. Searching for work in the digital era. http://www.pewinternet.org/2015/11/19/searching-for-work-in-the-digital-era/. Published November 19, 2015. Accessed February 23, 2017. 


\section{TABLES}

Table 1. Demographic characteristics of DPD directors who completed the online survey $(n=63)$

\begin{tabular}{llr} 
Characteristics & & $\mathbf{n}(\mathbf{\%})$ \\
\hline Age & $18-30$ & $0(0.0)$ \\
& $31-40$ & $15(23.8)$ \\
& $41-50$ & $12(19.0)$ \\
& $51-60$ & $21(33.3)$ \\
Years in Current Position & $61-70$ & $15(23.8)$ \\
& $71+$ & $0(0.0)$ \\
& $<1$ year & $14(22.2)$ \\
& $1-5$ years & $22(34.9)$ \\
& $6-10$ years & $15(23.8)$ \\
Highest level of Education & $11-15$ years & $4(6.3)$ \\
& $16-20$ years & $5(7.9)$ \\
Type of DPD Institution & $>20$ years & $3(4.8)$ \\
& Master's Degree & $29(46.8)$ \\
& Doctoral Degree & $33(53.2)$ \\
& Private & $14(22.2)$ \\
DI Offered at DPD Institution & Public & $49(77.8)$ \\
& Other & $0(0.0)$ \\
& DI Option only & $29(46.0)$ \\
& ISPP Option only & $8(12.7)$ \\
& Both DI and ISPP options & $4(6.3)$ \\
& Neither DI nor ISPP options & $22(34.9)$ \\
\hline
\end{tabular}




\begin{tabular}{llr}
\hline Table 2. Demographic characteristics of DI directors who completed the online survey & $(\mathrm{n}=97)$ \\
Characteristics & & $\mathbf{n}(\boldsymbol{\%})$ \\
\hline Age & $18-30$ & $2(2.1)$ \\
& $31-40$ & $21(21.6)$ \\
& $41-50$ & $30(30.9)$ \\
& $51-60$ & $32(33.0)$ \\
& $61-70$ & $12(12.4)$ \\
Types of DI Applications Reviewed & $71+$ & $0(0.0)$ \\
& Combined Master's/DI & $24(24.7)$ \\
& DI only & $72(74.2)$ \\
& ISPP only & $0(0.0)$ \\
& None & $1(1.0)$ \\
\hline
\end{tabular}


Table 3. Percentage of applicants evaluated by internships through online search engines or social networking sites $(n=92)$

\begin{tabular}{llr} 
Reviewer & & $\mathbf{n}(\boldsymbol{\%})$ \\
\hline Admission Board & $0 \%$ & $68(73.9)$ \\
& $1-9 \%$ & $8(8.7)$ \\
$10-25 \%$ & $5(5.4)$ \\
& $26-50 \%$ & $3(3.3)$ \\
DI Director & $51-75 \%$ & $2(2.2)$ \\
& $76-99 \%$ & $1(1.1)$ \\
& $100 \%$ & $5(5.4)$ \\
& $0 \%$ & $68(73.1)$ \\
$1-9 \%$ & $6(6.5)$ \\
$10-25 \%$ & $7(7.5)$ \\
& $26-50 \%$ & $3(3.2)$ \\
& $51-75 \%$ & $5(5.4)$ \\
& $76-99 \%$ & $0(0.0)$ \\
$100 \%$ & $4(4.3)$ \\
\hline
\end{tabular}


Table 4. Social networking topics DPD directors educate on to assist students with the DICAS application process $(n=56)$

\begin{tabular}{llr} 
Education Environment & & $\mathbf{n}(\mathbf{\%})$ \\
\hline Course Curriculum & E-portfolio's & $28(50.0)$ \\
& Social networking & $23(41.1)$ \\
& Professional online presence & $19(33.9)$ \\
& Personal branding & $7(12.5)$ \\
& Google quotient & $1(1.2)$ \\
& None & $16(28.6)$ \\
Informational Workshops & Other & $5(8.9)$ \\
& E-portfolio's & $19(33.9)$ \\
& Social networking & $19(33.9)$ \\
& Professional online presence & $17(30.4)$ \\
& Personal branding & $6(10.7)$ \\
& Google quotient & $1(1.2)$ \\
& None & $17(30.4)$ \\
\hline
\end{tabular}




\section{CHAPTER II: EXTENDED LITERATURE REVIEW}

\section{STEPS TO BECOME A REGISTERD DIETITIAN NUTRITIONIST}

A Registered Dietitian Nutritionist (RDN) is considered a food and nutrition expert able to translate nutritional sciences into practical implications for maintaining overall wellness and health. ${ }^{1}$ According the Bureau of Labor Statistics, a career demand in nutrition and dietetics is predicted to increase by $16 \%$ from $2014-2024 .^{2}$ However, the process to become an RDN is not an easy one. To become a credentialed RDN, one must complete a systematic process set by the Accreditation Counsel for Education in Nutrition and Dietetics (ACEND) of the Academy of Nutrition and Dietetics (AND).

First, one must complete the minimum of a bachelor degree at a US regionally accredited university or college. Students are obliged to enroll in a Didactic Program in Dietetics (DPD) with undergraduate curriculum consisting of a variety of subjects including nutritional science, food service management, biochemistry, and anatomy and physiology. ${ }^{3}$ However, this minimum requirement will be changed from a baccalaureate degree to the minimum of a graduate degree in 2024. ${ }^{4}$ Upon completion of a bachelor's degree from a DPD Program or completion of ACEND Didactic Program requirements, a DPD Program Director signs a verification statement stating the minimum ACEND Didactic Program Requirements have been met. ${ }^{5}$ Overall, the aim of completing all DPD program requirements and obtaining a verification statement is to grant an individual eligibility to persist through the systematic process and apply to an ACENDaccredited dietetic internship (DI) program.

Appointments into a DI are offered on a competitive basis and most commonly utilize a national computer matching process through Dietetic Internship Centralized Application Services (DICAS). Currently, all DI Programs must include a minimum of 1,200 hours of 
supervised practice and engage in competencies within the areas of clinical nutrition, food service management, and community nutrition. ${ }^{6}$ Similarly, after completion of an ACENDaccredited DI program, the DI director signs a verification statement stating the minimum ACEND supervised practice requirements have been met. This verification statement deems one eligible to take the Commission on Dietetic Registration (CDR) exam for dietitians, which is the final step in granting the credential of an RDN. ${ }^{5}$

Additionally, there are two alternative methods to the conventional DI route to becoming an RDN. One alternative route is completing a Coordinated Program (CP) which combines all required DPD course curriculum with at least 1,200 hours of supervised practice. CP graduates either hold a bachelor's or master's degree and are eligible to take the CRD exam. ${ }^{7}$ The second method is called an Individualized Supervised Practice Pathway (ISPP) which is intended for students who did not match to a DI. Most ISPP's require the individual to make arrangements themselves in finding preceptors to monitor their 1,200 hours of supervised practice; however, such a program also offers flexibility as the individual can tailor their ISPP to meet their personal needs. ${ }^{8}$ Similarly, ISPP programs meet all the minimum qualifications required for an individual to be eligible to take the CRD exam and receive the RDN credential.

Unfortunately, the shortage of ACEND accredited dietetic internships has created a national acceptance rate of approximately $50 \%$ throughout the past seven years. ${ }^{9}$ A record high of 5,192 dietetics students applied for dietetic internships during the April match of 2015 with 2,864 spots available. ${ }^{10}$ With few dietetic internship programs being created, this number of dietetic internship spots available has remained fairly consistent since $2003 .{ }^{11}$ 


\section{CENTRALIZED MATCH PROCESS WITH DICAS}

The Dietetic Internship Centralized Application Process (DICAS) was adopted in $2010^{` 12}$ which aimed to create an orderly and fair way to consider both applicants' and DI programs' preferences. Today, the majority of DI programs operate utilizing the DICAS application process. ${ }^{13}$ Applicants upload application materials to the computer-based software program and select DI programs they wish to be considered for. Subsequently, DI directors can access completed applications from applicants who have applied to their program. ${ }^{14}$

While there is no limit to the number of DI programs to which an applicant can apply, applicants must rank and prioritize each DI to which they apply through the contracted, mediator website, D\&D Digital. AND contracts D\&D Digital to manage the match portion of the overall process. ${ }^{13}$ On the whole, D\&D Digital is utilized by DI directors and DICAS applicants by ranking the candidates that applied to their program and the programs they are applying to respectively. Then, on match notification day, D\&D Digital utilizes algorithm statistics to find the "best match" for an applicant in an attempt to match both the applicants and DI preferences; however, when an applicant's rank order is exhausted, the applicant receives no match. ${ }^{15}$

\section{ONLINE VETTING OF SOCIAL NETWORKING SITES}

With dietetic internships being highly competitive, Dietetic Internship programs may need to out-source external applicant information to better differentiate between top candidates. According to a recent Pew research study, the use of social networking sites by American adults has increased by $7 \%$ since 2005 with $65 \%$ of adults now using some form of social networking. ${ }^{16}$ With an increased use of social networking within the general population, many recent studies have determined that employers and school admission boards research social networking sites to gain further information about applicants. A recent survey conducted by Kaplan Test Prep 
indicated over one-third (35\%) of college admissions offices have searched an applicant's social networking site to gather further information regarding the candidate. ${ }^{17}$

Importantly, literature reveals an increase in online-vetting reflected in the admission process for healthcare related fields as well. Researchers from University of Miami Miller School of Medicine conducted a study on the influence in social networking during the selection processes into medical school and residency. ${ }^{18}$ This study surveyed 600 medical school and residency application reviewers regarding the uses and attitudes towards researching applicant's social networking sites. The results indicated that $64 \%$ of survey respondents stated they were somewhat or very familiar with researching individuals social networking sites, 23\% reported medical school and residency programs should use internet searches on applicants, and 53\% reported programs should consider online professionalism when accepting students into medical school or residency programs.

A similar study was also conducted by researchers at St. George's School of Medicine to determine if residency program directors of general surgery and surgical subspecialties review applicant's social networking sites during the application process. ${ }^{19}$ Within this study, 250 surveys were collected from residency program directors indicating that from the $17 \%$ of respondents that answered yes to visiting social networking sites to obtain additional information about applicants, $33.3 \%$ of those respondents admitted to ranking an applicant lower after researching their social networking site.

Correspondingly, based on recent studies, online screening during the application process is on a rise for employers as well as. A Social Media Recruitment survey conducted for CareerBuilder reviewed 2,200 hiring and human resource manager's trends in resourcing applicant's social networking sites revealed over half (52\%) of employer's research job 
candidates online; up $9 \%$ from just one year prior. ${ }^{20}$ Importantly, this survey also indicated the lack of an online presence can negatively affect a candidate's application status with $35 \%$ of survey respondents claiming they were less likely to interview applicants they cannot find online.

\section{SOCIAL NETWORKING EDUCATION}

With an increase in use of social networking sites within the adult population and the increase in utilizing social networking sites in making admission and hiring decision, studies have been conducted researching how college programs should implement education on this topic of interest. Professional usage of social networking sites is of great concern among future healthcare providers because of ethical issues of unwarranted self-disclosure ${ }^{21}$ and client privacy concerns. ${ }^{22}$ One such study conducted by Tabor Flickinger utilized a needs assessment in creating curriculum for a 90-minute workshop to improve the knowledge and skills of professional social media use by medical students. ${ }^{23}$ The workshop curriculum covered activities with participants sharing web-searched examples of medical students on social media sites posting about medical topics and inappropriate posts on social networking sites. The workshop curriculum was evaluated via a qualitative post survey that was completed by 91 of the $120(75.8 \%)$ participants. Results reveal 56 positive comments were made with the common themes of enjoying the interactive style, case-based format, and opportunity for small group discussion. Also, 54 comments were made on suggestions for improvement of the curriculum such as clarification of instruction and providing additional resources. Overall, the workshop was well-received by medical students and can assist in future implementation of professional social networking education.

A second study conducted at a Canadian medical school recorded pre and post data screening information on 152 medical students whom attended a mandatory whole-class 
educational session on the subject of social media in medicine. ${ }^{24}$ Prior to the three-hour educational session, researchers found and reviewed $79.8 \%$ of the classes' Facebook profile pages in which a significant minority had information, such as pictures, status as a medical student, and comments visible to the general public. One month after the educational session, the Facebook profile search was repeated with a significant decrease in the proportion of students whose profile could be found using only a name search and those whom openly displayed a large number of pictures. Overall, the educational session was well received by the medical students with $90 \%$ of participants stating they agreed the issue of social media in medicine is an important topic that the session addressed properly.

\section{CONCLUSION}

Given the competitive nature of dietetic internships, maintaining a professional online presence may benefit a student during the DICAS application process. Currently, there is no set curriculum for DPD directors in educating dietetic students on the professional use of SNS, nor any indication on how SNS are utilized within the profession. Schulman et al. discovered SNS affect the selection of medical students into residency programs and the same outcomes could be predicted within the field of dietetics. ${ }^{18}$ There is a proposed need to evaluate the benefit of social networking education in dietetics' curriculum as well as DI directors' behaviors in online vetting during the DICAS match process due to limited research regarding these topics. The information gathered from this literature review has assisted with creating research questions for this surveyresearch study. This study aims to evaluate how DI directors utilize SNS during the DICAS match process as well as determine the effects of SNS education in DPD programs. 


\section{REFERENCES}

1. Academy of Nutrition and Dietetics. What is an RDN and NDRT? http://www.eatrightpro.org/resources/about-us/what-is-an-rdn-and-dtr. Accessed February 25, 2017.

2. Bureau of Labor Statistics. Dietitians and nutritionists. https://www.bls.gov/ooh/healthcare/dietitians-and-nutritionists.htm. Published 2016. Accessed March 9, 2017.

3. Academy of Nutrition and Dietetics. DPD graduates. http://www.eatrightpro.org /resources/career/become-an-rdn-or-dtr/dpd-graduates. Accessed April 12, 2016.

4. Commission on Dietetic Registration. Graduate degree registration eligibility requirement. https://www.cdrnet.org/vault/2459/web/files/ Graduate\%20Degree\%20FAQ.pdf. Published July 2013. Accessed February 21, 2017.

5. Accreditation Council for Education in Nutrition and Dietetics. FAQS about verification statements. http://www.eatrightpro.org/resource/acend/program-directors/programdirectors-faqs/faqs-about-verification-statements. Published August 2015. Accessed March 10, 2017.

6. Accreditation Council for Education in Nutrition and Dietetics. Dietetic internships. http://www.eatrightpro.org/resources/acend/accredited-programs/dietetic-internships. Accessed March 10, 2017.

7. Accreditation Council for Education in Nutrition and Dietetics. Coordinated programs in dietetics. http://www.eatrightpro.org/resources/acend/accredited-programs/coordinatedprograms-in-dietetics. Accessed February 23, 2017.

8. Penn State College of Health and Human Development. Types of dietetic internship programs. http://nutrition.hhdev.psu.edu/undergraduate/types-DI-programs. Accessed February 24, 2017.

9. Accreditation Council for Education in Nutrition and Dietetics. Availability of dietetic internship positions. http://www.eatrightpro.org/resource/acend/students-and-advancingeducation/dietetic-internship-match-students/availability-of-dietetic-internship-positions. Accessed April 14, 2016.

10. Accreditation Council for Education in Nutrition and Dietetics. ACEND update. http://www.eatrightpro.org/ /media/eatrightpro\%20files/acend/acend_update_august_20 15.ashx. Published August 2015. Accessed April 7, 2016.

11. Sherry AR. The dearth of dietetic internships. Today's Dietitian. 2015;17(3):18-20.

12. Shanley ER, Johnston RE, Young LO, Gates GE, Chung U, Lusk M. Centralized online dietetic internship application. Retrieved from 
file:///C:/Users/Noel\%20Konken/Downloads/DICAS_Webinar_Slides_05-20-

2010\%20(1).pdf. Published 2010. Accessed February 23, 2017.

13. Accreditation Council for Education in Nutrition and Dietetics. Top 10 questions about computer matching for dietetic internships.

http://www.eatrightpro.org/resource/acend/students-and-advancing-education/dieteticinternship-match-students/top-10-questions-about-computer-matching-for-dieteticinternships. Published March 2013. Accessed March 6, 2017.

14. D\&D Digital. Internship matching questions and answers. https://www.dnddigital.com/ada/questions.php. Published 2015. Accessed March 10, 2017.

15. Accreditation Council for Education in Nutrition and Dietetics. Dietetic internship match: students. http://www.eatrightpro.org/resources/acend/students-and-advancingeducation/dietetic-internship-match-students. Accessed February 23, 2017.

16. Perrin A. Pew Research Center. Social media usage: 2005-2015. http://www.pewinternet.org/2015/10/08/social-networking-usage-2005-2015/. Published: October 8, 2015. Accessed April 12, 2016.

17. Kaplan Test Prep. Kaplan test prep survey: Percentage of college admissions officers who visit applicants' social networking pages continues to grow-but most students shrug. http://press.kaptest.com/press-releases/kaplan-test-prep-survey-percentage-ofcollege-admissions-officers-who-visit-applicants-social-networking-pages-continues-togrow-but-most-students-shrug. Published November 20, 2014. Accessed April 9, 2016.

18. Schulman CI, Kuchkarian, FM, Withum, KF, et al. Influence of social networking websites on medical school and residency selection process. Postgrad Med J. 2013;89(1049):126-130.

19. Go PH, Klaassen, Z, Chamberlain RS. Original report: Attitudes and Practices of Surgery Residency Program Directors Toward the Use of Social Networking Profiles to Select Residency Candidates: A Nationwide Survey Analysis. J Surg Edu. 2012;69(3):292-300.

20. CareerBuilder. http://www.careerbuilder.com/share/aboutus/ pressreleasesdetail.aspx?sd=5\%2F14\%2F2015\&id=pr893\&ed=12\%2F31\%2F2015. Published 2015. Accessed April 10, 2016.

21. Anderson SC, Guyton MR. Ethics in an Age of Information Seekers: A Survey of Licensed Healthcare Providers about Online Social Networking. J Tech Hum Serv. 2013;31(2):112-128.

22. Henderson M, Dahnke, MD. The Ethical Use of Social Media in Nursing Practice. Medsurg Nurs.2015;24(1):62-64. 
23. Flickinger TE, O'Hagan T, Chisolm MS. Developing a Curriculum to Promote Professionalism for Medical Students Using Social Media: Pilot of a Workshop and Blog-Based Intervention. J Med Inter Reas. 2015;17(12):1-11.

24. Walton JM, White J, Ross S. What's on YOUR Facebook profile? Evaluation of an educational intervention to promote appropriate use of privacy settings by medical students on social networking sites. Med Edu Online. 2015;20 


\section{APPENDIX A: SURVEY INSTRUMENT FOR DPD DIRECTORS}

1. Are you currently serving as the DPD director at an ACEND accredited DPD program? 0 : Yes

1: No

2. How many years have you served as the DPD director of your current institution?
0 : Less than 1 year
1: $1-5$ years
2: 6-10 years
3: $11-15$ years
4: $16-20$ years
5: Greater than 20 years

3. What is the highest level of education you have completed at this time?

0: Master's Degree 1: Doctoral Degree

4. Is your DPD college or university considered a public or private institution?
0 : Private
1: Public
3: Other

5. Is there a Dietetic Internship (DI) or Individualized Supervised Practice Pathway (ISPP) offered at your undergraduate DPD institution?

0 : DI option only

1:ISPP option only

3: Both DI and ISPP options available

4: Neither DI nor ISPP options available

6. If your undergraduate DPD institution offers a DI or ISPP, does the DPD director sit on the advisory board for DI or ISPP candidate selection?

0: Neither DI nor ISPP options available

1: Yes, DI nor ISPP options available

2: No, DPD director does not sit on advisory board

7. In what Geographic area of Nutrition and Dietetic Educators and Preceptors (NDEP) is your DPD program located?

Area 1: Alaska, California, Montana, Oregon, Wyoming, Idaho, Hawaii, Washington Area 2: Iowa, Minnesota, Michigan, Missouri, Nebraska, North Dakota, South Dakota, Wisconsin

Area 3: Alabama, Arkansas, Florida, Georgia, Louisiana, Mississippi, South Carolina, Puerto Rico Area

Area 4: Arizona, Colorado, Kansas, Nevada, New Mexico, Oklahoma, Texas, Utah

Area 5: Indiana, Illinois, Kentucky, Ohio, Tennessee, West Virginia

Area 6: Maryland, North Carolina, Virginia, Delaware, Pennsylvania, District of Columbia

Area 7: New Jersey, New York, Maine, Rhode Island, Massachusetts, Vermont, Connecticut, New Hampshire, International Members

8. During which academic year and semester do you introduce DICAS to undergraduate dietetics students?

$\begin{array}{lll}\text { 1: Freshman } & \text { 2: Sophomore Junior } \quad 4: \text { Senior }\end{array}$ 
9. During which semester do you introduce DICAS to undergraduate dietetics students? 1: Fall 2: Spring

10. Referring to the Spring 2016 Dietetic Internship match, please provide the following information for you specific DPD:

Total number of students, both current and past, that applied during the spring 2015 Dietetic Internship match:

Total number of students, both current and past, that were matched during the spring 2015 Dietetic Internship match, including Second Round match:

Total number of students expected to receive a DPD Verification Statement between Match Notification Day (April 3 ${ }^{\text {rd }}$ ) and the start of the 2016-2017 academic school year:

11. Considering only students who previously graduated from your DPD (students graduating fall 2015 or earlier), please provide the following information about the spring 2016 Dietetic Internship match for your specific DPD:

Total number of students who previously graduated from your DPD program that applied during the spring 2016 Dietetic Internship match:

Total number of students who previously graduated from your DPD that were matched during the spring 2016 Dietetic Internship match, including Second Round Match:

12. Which of the following topics are incorporated into your course curriculum at your specific DPD Institution to assist students with the DICAS application process? Please check all that apply.

Electronic Portfolio's (e-portfolios)

Social Networking

Professional Online Presence

Personal Branding

Google quotient

Other

None

13. Which of the following topics are incorporated into informational workshops at your specific DPD Institution to assist students with the DICAS application process? Please check all that apply.

Electronic Portfolio's (e-portfolios)

Social Networking

Professional Online Presence

Google quotient

Personal Branding

Other

None 
14. Please consider your perceived effectiveness of the following topics to assist students in being matched to Dietetic Internships. Please note that only topics offered at your specific DPD in preparation for the spring 2016 Dietetic Internship match should be considered for effectiveness, while strategies not currently implemented at your DPD should be denoted with the "Specific Intervention not offered at DPD" option.

Electronic Portfolios:
0 : Specific topic not offered at DPD
1: Very Ineffective
2: Ineffective
3: Slightly ineffective
4: Neutral
5: Slightly effective
6: Effective
7: Very effective

Social Networking:

0: Specific topic not offered at DPD 1: Very Ineffective

3: Slightly ineffective

4: Neutral

2: Ineffective

6: Effective

7: Very effective

5: Slightly effective

Professional Online Presence:

0: Specific topic not offered at DPD 1: Very Ineffective

3: Slightly ineffective

4: Neutral

2: Ineffective

6: Effective

7: Very effective

5: Slightly effective

Personal Branding:

0: Specific topic not offered at DPD 1: Very Ineffective

3: Slightly ineffective

4: Neutral

2: Ineffective

6: Effective

7: Very effective

5: Slightly effective

Google Quotient:

0 : Specific topic not offered at DPD 1: Very Ineffective

3: Slightly ineffective

4: Neutral

2: Ineffective

6: Effective

7: Very effective

5: Slightly effective

15. Which of the topics listed below do you believe is, or would be, the most effective topic for assisting your students with the Dietetic Internship match process? Please select 1 answer.
1: Electronic Portfolio's (e-portfolios)
2: Social Networking
3: Professional Online Presence
4: Personal Branding
5: Google Quotient
0 : Other

16. How important do you believe educating students on the influences of social media are in determining whether a certain individual will be matched to a Dietetic Internship?
1: Not Important At All
2: Slightly Important
3: Important
4: Moderately Important
5: Very Important
6: Extremely Important
0: Not Sure/Not Applicable

17. Dietetic internship program admissions should use: 
Internet search engines (i.e. Google) to obtain additional information about applicants that is not included in their applications.
1: Strong disagree
2: Disagree
3: Neutral
4: Agree
5: Strongly Agree

Social networking web sites (1.e Twitter, Facebook, etc.) to obtain additional information about applicants that is not included in their applications
1: Strong disagree
2: Disagree
3: Neutral
4: Agree
5: Strongly Agree

18. As a DPD Director, I normally:

Search for additional information on my students through internet search engines

(i.e. Google).
1: Strong disagree
2: Disagree
3: Neutral
4: Agree
5: Strongly Agree

Research my students on social networking web sites (i.e. Facebook, Twitter, etc.)
1: Strong disagree
2: Disagree
3: Neutral
4: Agree
5: Strongly Agree

19. It is a violation of privacy for dietetic internship program admission boards to search for an applicant's name on:

Internet search engines (i.e. Google).

$\begin{array}{lll}\text { 1: } \text { Strong disagree } & \text { 2: Disagree } & \text { 3: Neutral } \\ \text { 4: Agree } & \text { 5: Strongly Agree } & \\ \text { networking web sites } & & \\ \text { 1: Strong disagree } & \text { 2: Disagree } & \text { 3: Neutral } \\ \text { 4: Agree } & \text { 5. Strongly Agree } & \end{array}$

20. To what extent do you agree or disagree that:

Online professionalism should be a factor for admission into dietetic internship programs
1: Strong disagree
2: Disagree
3: Neutral
4: Agree
5. Strongly Agree

Unprofessional information (i.e. questionable group membership, photos, wall posts, and /or comments) on an applicant's social networking web site profile would compromise their admission into our dietetic internship program.
1: Strong disagree
2: Disagree
3: Neutral
4: Agree
5. Strongly Agree

Dietetic professionalism involves keeping activity and profiles on social networking web sites professional, or not having one at all.
1: Strong disagree
2: Disagree
3: Neutral
4: Agree
5. Strongly Agree

Educating students on the influences of social media are very important in 
determining whether a certain individual will be matched to a Dietetic Internship.

$\begin{array}{lll}\text { 1: Strong disagree } & \text { 2: Disagree } & \text { 3: Neutral } \\ \text { 4: Agree } & \text { 5. Strongly Agree }\end{array}$

This survey has changed my view on the relationship between admission into a Dietetic Internship and social networking web sites.
1: Strong disagree
2: Disagree
3: Neutral
4: Agree
5. Strongly Agree 


\section{APPENDIX B: SURVEY INSTRUMENT FOR DI DIRECTORS}

1. Are you currently serving as the DI director at an ACEND accredited DPD program? 0 : Yes

1: No

2. What is your age?
0 : $18-30$ years old
1: $31-40$ years old
2: 41-50 years old

3: 51-60 years old

4: 61-70 years old

5: 71 years or older

3. In what Geographic area of Nutrition and Dietetic Educators and Preceptors (NDEP) is your DPD program located?

Area 1: Alaska, California, Montana, Oregon, Wyoming, Idaho, Hawaii, Washington Area 2: Iowa, Minnesota, Michigan, Missouri, Nebraska, North Dakota, South Dakota, Wisconsin

Area 3: Alabama, Arkansas, Florida, Georgia, Louisiana, Mississippi, South Carolina, Puerto Rico Area

Area 4: Arizona, Colorado, Kansas, Nevada, New Mexico, Oklahoma, Texas, Utah

Area 5: Indiana, Illinois, Kentucky, Ohio, Tennessee, West Virginia

Area 6: Maryland, North Carolina, Virginia, Delaware, Pennsylvania, District of Columbia

Area 7: New Jersey, New York, Maine, Rhode Island, Massachusetts, Vermont, Connecticut, New Hampshire, International Members

4. Which of the following best describes the dietetic internship program applications that you review?

1: Combined Masters and Dietetic Internship applications

2: Dietetic Internship applications

3: ISPP applications

4: I do not review applications

5. During the spring 2016 match, how many applications did your DI program receive?

6. If your dietetic internship program has a profile on a social networking site, please select each type of social networking site that applies:

$\begin{array}{lll}\text { Myspace } & \text { Facebook } & \text { Twitter } \\ \text { LinkedIn } & \text { Friendster } & \text { Instagram } \\ \text { Hi5 } & \text { Orkut } & \text { Bebo } \\ \text { My DI program does not participate in social media } & \text { Other }\end{array}$

7. If you have a personal profile on a social networking web site, please select each social networking site in which you are personally involved:

Myspace

Facebook

Twitter 


$\begin{array}{lll}\text { LinkedIn } & \text { Friendster } & \text { Instagram } \\ \text { Hi5 } & \text { Orkut } & \text { Bebo } \\ \text { I do not participate in social } & \text { media } & \text { Other }\end{array}$

8. How familiar are you with researching individuals on:

Internet search engines (i.e. Google)
1: Not at all familiar
2: Somewhat familiar
3: Very familiar

Social networking sites (i.e. Facebook)
1: Not at all familiar
2: Somewhat familiar
3: Very familiar

9. What online research methods has your dietetic internship admission board used to evaluate potential interns?

0 : None

1: Social networking websites (i.e. Facebook)

2: Internet search engines (i.e. Google)

3: Both

4: Don't know

5: I am the only one to review applications

10. What percentage of applicants does your dietetic internship admission board evaluate online through social engines or social networking sites?
$0: 0 \%$
1: $1-9 \%$
2: $10-25 \%$
$3: 26-50 \%$
4: $51-75 \%$
$5: 76-99 \%$
6: $100 \%$

11. What online research methods have you used to evaluate potential interns or students?

0 : None

1: Social networking websites (i.e. Facebook)

2: Internet search engines (i.e. Google)

3: Both

4: Don't know

12. What percentage of applicants do you evaluate online through social engines or social networking sites?
$0: 0 \%$
1: $1-9 \%$
2: $10-25 \%$
$3: 26-50 \%$
4: $51-75 \%$
$5: 76-99 \%$
6: $100 \%$

13. Dietetic internship program admissions should use:

Internet search engines (i.e. Google) to obtain additional information about applicants that is not included in their applications.
1: Strong disagree
2: Disagree
3: Neutral
4: Agree
5: Strongly Agree

Social networking web sites (1.e Twitter, Facebook, etc.) to obtain additional information about applicants that is not included in their applications
1: Strong disagree
2: Disagree
3: Neutral 

4: Agree
5: Strongly Agree

14. Our admission board normally search for additional information on applicants through:

Internet search engines (i.e. Google)
1: Strong disagree
2: Disagree
3: Neutral
4: Agree
5: Strongly Agree

Social networking web sites (i.e. Twitter, Facebook, etc.)
1: Strong disagree
2: Disagree
3: Neutral
4: Agree
5: Strongly Agree

15. Out admission board plans to search for potential intern information on:

Internet search engines in the future
1: Strong disagree
2: Disagree
3: Neutral
4: Agree
5: Strongly Agree

Social networking web sites in the future
1: Strong disagree
2: Disagree
3: Neutral
4: Agree
5: Strongly Agree

16. It is a violation of privacy for dietetic internship program admission boards to search for an applicant's name on:

Internet search engines

1: Strong disagree

4: Agree

Social networking web sites

1: Strong disagree

4: Agree
2: Disagree

5: Strongly Agree

2: Disagree

5: Strongly Agree
3: Neutral

3: Neutral

17. To what extent do you agree or disagree that:

Online professionalism should be a factor for admission into dietetic internship programs
1: Strong disagree
2: Disagree
3: Neutral
4: Agree
5. Strongly Agree

Unprofessional information (i.e. questionable group membership, photos, wall posts, and /or comments) on an applicant's social networking web site profile would compromise their admission into our dietetic internship program.
1: Strong disagree
2: Disagree
3: Neutral
4: Agree
5. Strongly Agree

Dietetic professionalism involves keeping activity and profiles on social networking web sites professional, or not having one at all.
1: Strong disagree
2: Disagree
3: Neutral
4: Agree
5. Strongly Agree 
18. Our admission board has decided to not admit a student and/or applicant because of unprofessionalism/questionable information found on:

Internet search engines (i.e. Google)

1: Strong disagree

2: Disagree

3: Neutral

4: Agree

5. Strongly Agree

Social networking web sites (i.e. Facebook, Twitter)

1: Strong disagree

2: Disagree

3: Neutral

4: Agree

5. Strongly Agree

19. Finding no information online about an applicant would:

Negatively affect the applicant's application status
1: Strong disagree
2: Disagree
3: Neutral
4: Agree
5. Strongly Agree

20. This survey has changed my view on the relationship betweeb:

Admission and social networking websites
1: Strong disagree
2: Disagree
3: Neutral
4: Agree
5. Strongly Agree 


\section{APPENDIX C: INITIAL SURVEY ACCESS EMAIL FOR DPD DIRECTORS}

Subject: Thesis Research: Influence of social networking sites on selection into a DI

\section{Dear DPD Director,}

My name is Noël Konken and I am a graduate student under the direction of Dr. Julie

Schumacher in the Department of Family and Consumer Sciences at Illinois State University. I am conducting a research study for my Master's thesis to evaluate the current uses of online vetting by ACEND accredited Dietetic Internship programs during the application process and compare them to DPD institution's education on professional use of social networking sites.

I am requesting your voluntary participation, which will likely take less than fifteen minutes of your time. If you are willing to participate, please complete the following online survey about your current DPD institution: <Insert link here>

I greatly appreciate you taking your time. This survey hopes to benefit DPD programs in identifying if education on professional social networking should be incorporated into DPD program curriculum to assist students in apply to Dietetic Internships.

If you have any questions concerning the research study, please contact me at nlkonke@ilstu.edu; (XXX) XXX-XXXX or Dr. Julie Schumacher at jmraede@ilstu.edu; (XXX) $\mathrm{XXX}-\mathrm{XXX}$. Your time is greatly appreciated.

Thank you.

Noël Konken 


\section{APPENDIX D: INITIAL SURVEY ACCESS EMAIL FOR DI DIRECTORS}

Subject: Thesis Research: Influence of social networking sites on selection into a DI

\section{Dear DI Director,}

My name is Noël Konken and I am a graduate student under the direction of Dr. Julie

Schumacher in the Department of Family and Consumer Sciences at Illinois State University. I am conducting a research study for my Master's thesis to evaluate the current uses of online vetting by ACEND accredited Dietetic Internship programs during the application process and compare them to DPD institution's education on professional use of social networking sites.

I am requesting your voluntary participation, which will likely take less than fifteen minutes of your time. If you are willing to participate, please complete the following online survey about your current DI program: <Insert link here>

I greatly appreciate you taking your time. This survey hopes to benefit DPD programs in identifying if education on professional social networking should be incorporated into DPD program curriculum to assist students in apply to Dietetic Internships.

If you have any questions concerning the research study, please contact me at nlkonke@ilstu.edu; (XXX) XXX-XXXX or Dr. Julie Schumacher at jmraede@ilstu.edu; (XXX) $\mathrm{XXX}-\mathrm{XXXX}$. Your time is greatly appreciated.

Thank you.

Noël Konken 


\section{APPENDIX E: INFORMED CONSENT FOR DPD DIRECTOR}

\section{Dear DPD Director:}

My name is Noël Konken and I am a graduate student under the direction of Dr. Julie Schumacher in the Department of Family and Consumer Sciences at Illinois State University. I am conducting a research study for my Master's thesis to evaluate the current uses of online vetting by ACEND accredited Dietetic Internship programs during the application process and compare them to DPD institution's education on professional use of social networking sites.

I am requesting your participation, which will likely take less than fifteen minutes of your time and will involve completing an online survey about your current DPD institution. The survey will include questions regarding your current role working with DPD students, education topics your program offers to assist students with the DICAS application, basic demographic items, and specific data regarding your DPD institution's DI match rate for the spring 2016 DICAS matching period.

Your participation in this study is voluntary. However, all participants are required to be 18 years of age or older. If you choose not to participate, skip any questions in the survey, or withdraw from the study at any time, there will be no penalty or loss of benefits. The results of the study will be used for thesis research and may be published. Your responses will remain anonymous and any information that might allow someone to identify you or your institution will not be disclosed. All data collected from the study will be password protected.

There are no risks involved with participation beyond those of everyday life. Although there may be no direct benefit to you, a possible benefit of your participation is to identify if education on professional social networking should be incorporated into DPD program curriculum to assist students applying to Dietetic Internships and offer suggestions of which social networking sites are most resourced by Dietetic Internship Directors. If you have any questions concerning the research study, please contact me at nlkonke@ilstu.edu; (XXX) XXX-XXXX or Dr. Julie Schumacher at jmraede@ilstu.edu; (XXX) XXX-XXXX. Your time is greatly appreciated. Thank you.

Sincerely,

Noel Konken 


\section{APPENDIX F: INFORMED CONSENT FOR DI DIRECTOR}

Dear Dietetic Internship Director:

My name is Noël Konken and I am a graduate student under the direction of Dr. Julie Schumacher in the Department of Family and Consumer Sciences at Illinois State University. I am conducting a research study for my Master's thesis to evaluate the current uses of online vetting by ACEND accredited Dietetic Internship programs during the application process and compare them to DPD institution's education on professional use of social networking sites.

I am requesting your participation, which will likely take less than fifteen minutes of your time and will involve completing an online survey about your current DI program. The survey will include questions regarding your current role in reviewing DI applications, social networking sites your program uses, your DI program's online vetting trends, and your beliefs on personal privacy.

Your participation in this study is voluntary. However, all participants are required to be 18 years of age or older. If you choose not to participate, skip any questions in the survey, or withdraw from the study at any time, there will be no penalty or loss of benefits. The results of the study will be used for thesis research and may be published. Your responses will remain anonymous and any information that might allow someone to identify you or your institution will not be disclosed. All data collected from the study will be password protected.

There are no risks involved with participation beyond those of everyday life. Although there may be no direct benefit to you, a possible benefit of your participation is to identify if education on professional social networking should be incorporated into DPD program curriculum to assist students applying to Dietetic Internships and offer suggestions of which social networking sites are most resourced by Dietetic Internship Directors. If you have any questions concerning the research study, please contact me at nlkonke@ilstu.edu; (XXX) XXX-XXXX or Dr. Julie Schumacher at jmraede@ilstu.edu; $(\mathrm{XXX}) \mathrm{XXX}-\mathrm{XXXX}$. Your time is greatly appreciated. Thank you.

Sincerely,

Noel Konken 


\section{APPENDIX G: REMINDER EMAIL \#1 FOR DPD DIRECTORS}

\section{Dear DPD Director,}

Thank you if you have already completed the survey on Assessing the Online Branding of Dietetics Students. This is a reminder for those who have yet to complete the survey that you are invited to participate in this Master's thesis research through June 6th, 2016.

This voluntary survey will likely take less than fifteen minutes of your time and can be found at: <insert link here>

I greatly appreciate you taking your time. This survey hopes to benefit DPD programs in identifying if education on professional social networking should be incorporated into DPD program curriculum to assist students in applying to Dietetic Internships.

If you have any questions concerning the research study, please contact me at nlkonke@ilstu.edu; (XXX) XXX-XXXX or Dr. Julie Schumacher at jmraede@ilstu.edu; (XXX) $\mathrm{XXX}-\mathrm{XXXX}$. Your time is greatly appreciated.

Thank you,

Noël Konken 


\section{APPENDIX H: REMINDER EMAIL \#1 FOR DI DIRECTORS}

\section{Dear DI Director,}

Thank you if you have already completed the survey on Assessing the Online Branding of Dietetics Students. This is a reminder for those who have yet to complete the survey that you are invited to participate in this Master's thesis research through June 6th, 2016.

This voluntary survey will likely take less than fifteen minutes of your time and can be found at: <insert link here>

I greatly appreciate you taking your time. This survey hopes to benefit DPD programs in identifying if education on professional social networking should be incorporated into DPD program curriculum to assist students in applying to Dietetic Internships.

If you have any questions concerning the research study, please contact me at nlkonke@ilstu.edu; (XXX) XXX-XXXX or Dr. Julie Schumacher at jmraede@ilstu.edu; (XXX) $\mathrm{XXX}-\mathrm{XXXX}$. Your time is greatly appreciated.

Thank you,

Noël Konken 


\section{APPENDIX I: FINAL REMINDER EMAIL FOR DPD DIRECTORS}

\section{Dear DPD Director,}

Thank you if you have already completed the survey on Assessing the Online Branding of Dietetics Students. This is a final reminder for those who have yet to complete the survey that you are invited to participate in this Master's thesis research through June 6th, 2016.

This voluntary survey will likely take less than fifteen minutes of your time and can be found at: <insert link here>

I greatly appreciate you taking your time. This survey hopes to benefit DPD programs in identifying if education on professional social networking should be incorporated into DPD program curriculum to assist students in applying to Dietetic Internships.

If you have any questions concerning the research study, please contact me at nlkonke@ilstu.edu; (XXX) XXX-XXXX or Dr. Julie Schumacher at jmraede@ilstu.edu; (XXX) $\mathrm{XXX}-\mathrm{XXXX}$. Your time is greatly appreciated.

Thank you,

Noël Konken 


\section{APPENDIX J: FINAL REMINDER EMAIL FOR DI DIRECTORS}

\section{Dear DI Director,}

Thank you if you have already completed the survey on Assessing the Online Branding of Dietetics Students. This is a final reminder message for those who have yet to complete the survey that you are invited to participate in this Master's thesis research through June 6th, 2016.

This voluntary survey will likely take less than fifteen minutes of your time and can be found at: <insert link here>

I greatly appreciate you taking your time. This survey hopes to benefit DPD programs in identifying if education on professional social networking should be incorporated into DPD program curriculum to assist students in applying to Dietetic Internships.

If you have any questions concerning the research study, please contact me at nlkonke@ilstu.edu; (XXX) XXX-XXXX or Dr. Julie Schumacher at jmraede@ilstu.edu; (XXX) $\mathrm{XXX}-\mathrm{XXXX}$. Your time is greatly appreciated.

Thank you,

Noël Konken 